\title{
The effects of stacking sequence on the penetration-resistant behaviors of T800 carbon fiber composite plates under low-velocity impact loading
}

\author{
Furqan Ahmad ${ }^{1}$, Jung-Wuk Hong ${ }^{1}$, Heung Soap Choi ${ }^{2}$, Soo-Jin Park ${ }^{3}$ and Myung Kyun Park, \\ ${ }^{1}$ Department of Civil and Environmental Engineering, Korea Advanced Institute of Science and Technology, Daejeon 305-338, Korea \\ ${ }^{2}$ Department of Mechanical and Design Engineering, Hongik University, Sejong 339-701, Korea \\ ${ }^{3}$ Department of Chemistry, Inha University, Incheon 402-751, Korea \\ ${ }^{4}$ Department of Mechanical Engineering, Myongji University, Yongin 449-728, Korea
}

\section{Article Info}

Received 9 December 2014 Accepted 6 March 2015

*Corresponding Author

E-mail: pmk@mju.ac.kr

Tel: $+82-31-330-6425$

\section{Open Access}

DOI: http://dx.doi.org/

10.5714/CL.2015.16.2.107

This is an Open Access article distributed under the terms of the Creative Commons Attribution Non-Commercial License (http://creativecommons.org/licenses/ by-nc/3.0/) which permits unrestricted non-commercial use, distribution, and reproduction in any medium, provided the original work is properly cited.

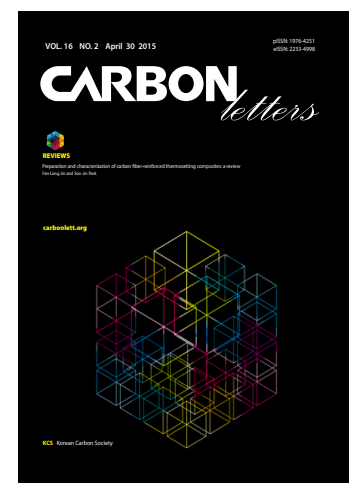

http://carbonlett.org

pISSN: $1976-4251$

elSSN: 2233-4998

Copyright $\odot$ Korean Carbon Society

\begin{abstract}
Impact damages induced by a low-velocity impact load on carbon fiber reinforced polymer (CFRP) composite plates fabricated with various stacking sequences were studied experimentally. The impact responses of the CFRP composite plates were significantly affected by the laminate stacking sequences. Three types of specimens, specifically quasi-isotropic, unidirectional, and cross-ply, were tested by a constant impact carrying the same impact energy level. An impact load of $3.44 \mathrm{~kg}$, corresponding to $23.62 \mathrm{~J}$, was applied to the center of each plate supported at the boundaries. The unidirectional composite plate showed the worst impact resistance and broke completely into two parts; this was followed by the quasi-isotropic lay-up plate that was perforated by the impact. The cross-ply composite plate exhibited the best resistance to the low-velocity impact load; in this case, the impactor bounced back. Impact parameters such as the peak impact force and absorbed energy were evaluated and compared for the impact resistant characterization of the composites made by different stacking sequences.
\end{abstract}

Key words: stacking sequence, penetration-resistance, low-velocity impact, impact force, penetration impact energy

\section{Introduction}

For several decades, fiber-reinforced laminated composite materials have been widely used for many different products such as aerospace and ground and marine transportation vehicles as well as wind energy structural components, for which weight reduction is considered as the most critical aspect and could be accomplished using light-weight characteristic materials with relatively high specific strength or specific stiffness compared to more conventional structural materials.

It is well-known that a fiber-reinforced composite material is a type of hybrid material system that consists of a polymeric matrix reinforced with a fibrous form of load-carrying materials [1]. The maximum use of a composite material in an aircraft structure can be found in the manufacturing of Boeing 787 airliners, $50 \%$ of which have now been replaced by carbon fiber reinforced polymer (CFRP) composites. Despite the substantial merits and successful uses of the composite materials as various structural building blocks, especially in aerospace applications [2], there also has been concern that carbon fiber reinforced composites are susceptible to low-velocity impacts that may cause significant damage, such as matrix cracking, interlayer delamination, fiber-matrix interfacial disbanding and fiber breakage [3-7].

Certain polymeric matrices such as an epoxy matrix might have brittle failure characteristics, making them susceptible to internal damage generation that was caused mainly by an impact and eventually, affects the overall structural integrity as well as the local stiffness of 
the material $[8,9]$. Yang and Sun [10] presented the experimental indentation law through static indentation tests on composite laminates. Choi and Lim [11] proposed a linearized contact law for low-velocity impact analysis of composite laminates and compared it with the modified Hertzian contact law. Sun and Chattopadhyay [12], Dobyns [13], Ramkumar and Chen [14] employed the first-order shear deformation theory developed by Whitney and Pagano [15] in conjunction with the Hertzian contact law to study the impact behavior of laminated composite plates. Ganapathy and Rao [16] predicted the damage growth in laminated composite plates and in cylindrical/spherical shell panels that were subjected to low-velocity impact.

This paper presents the results of an investigation on the damage caused by low-velocity impacts on T800 carbon fiber composite plates fabricated with different stacking sequences. We conducted experimental testing to investigate the initiation and evolution of the impact damage in CFRP composite plates with different stacking sequences under the same level of impact energy. Software was developed in LabVIEW to record the impact load and energy absorbed during low-velocity impact events. To perform the impact tests, an instrumented drop test machine was used, and the impact energy was set to $23.62 \mathrm{~J}$.

\section{Experimentation}

\subsection{Materials and specimens}

The material used as the substrate for the specimens in this study is an epoxy resin toughened at $350^{\circ} \mathrm{F}$ and pre-impregnat-

(a)

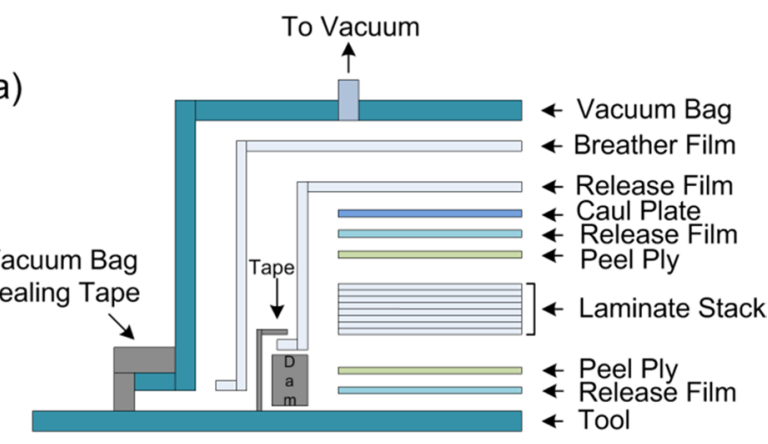

(b)

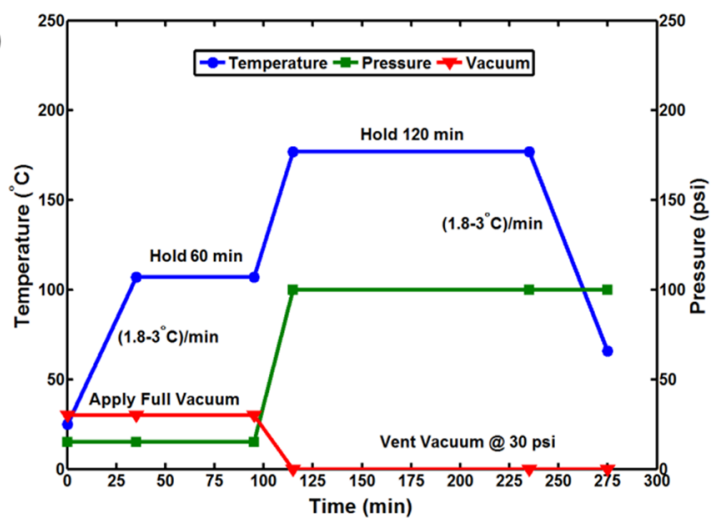

Fig. 1. Fabrication of carbon fiber reinforced polymer laminate: (a) bagging scheme for curing, (b) autoclave curing cycle. ed with unidirectional carbon fibers of type Toray T800/3900. The material consists of T800 carbon fibers impregnated in an epoxy resin in which the resin holds the longitudinal continuous fibers together to form sheets of CFRP composite panels. It is currently being used in the construction of the Boeing 787. The curing cycle of the material is shown in Fig. 1. Large CFRP composite panels of $1000 \times 1000 \times 1.5 \mathrm{~mm}$ were fabricated and cut to produce the laminated plate specimens of $125 \times 125 \times$ $1.5 \mathrm{~mm}$ with 8 plies. The averaged fiber volume fraction of a specimen was $55.5 \%$. The mechanical properties of a lamina are listed in Table 1. In this study, five types of CFRP composite plates with different stacking sequences were tested. They were made from rolls of pre-impregnated materials and assembled according to the desired stacking sequences listed in Table 2.

\subsection{Experimental setup}

The experimental setup used for the low-velocity impact testing is shown in Fig. 2. A mini-drop tower machine was used to conduct the low-velocity impact tests. Sophisticated instruments were used with the drop machine to record the impact events,

Table 1. The material properties of the unidirectional layer

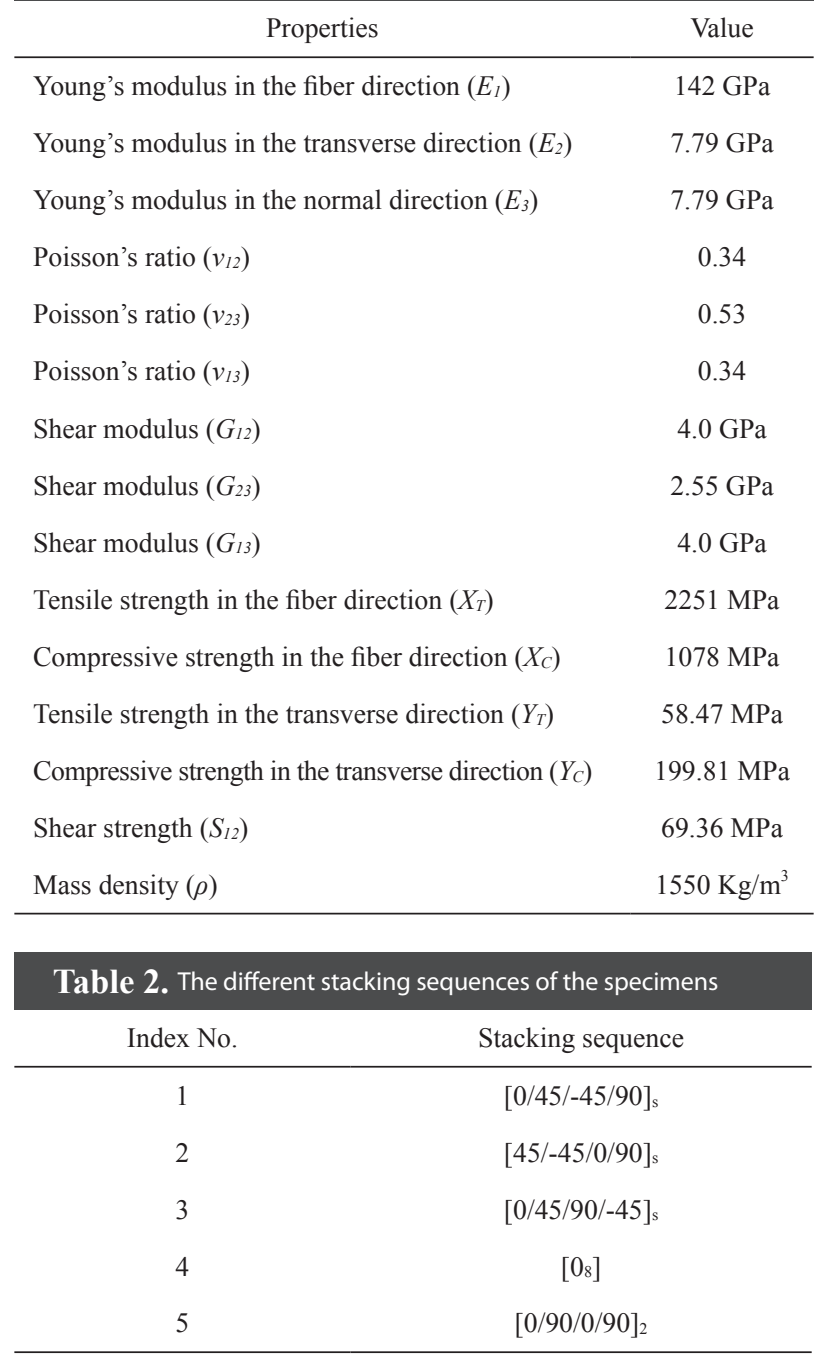




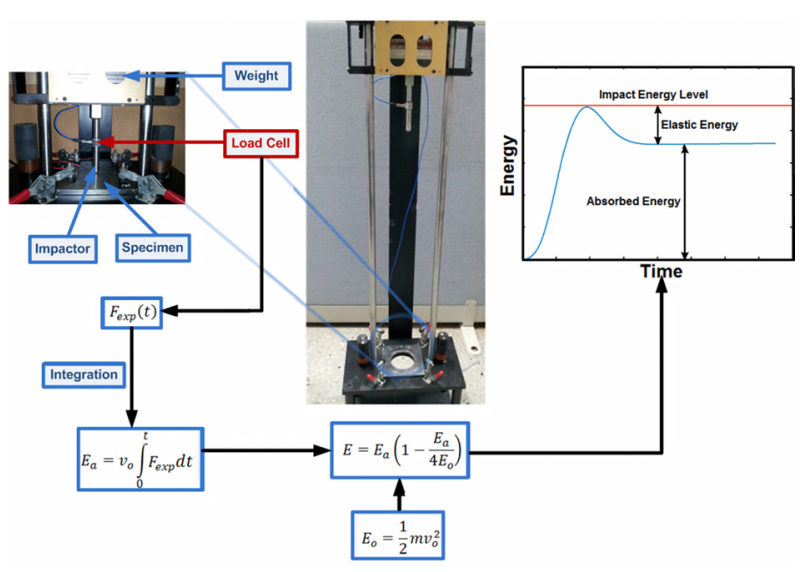

Fig. 2. The experimental setup for the low-velocity impact tests.

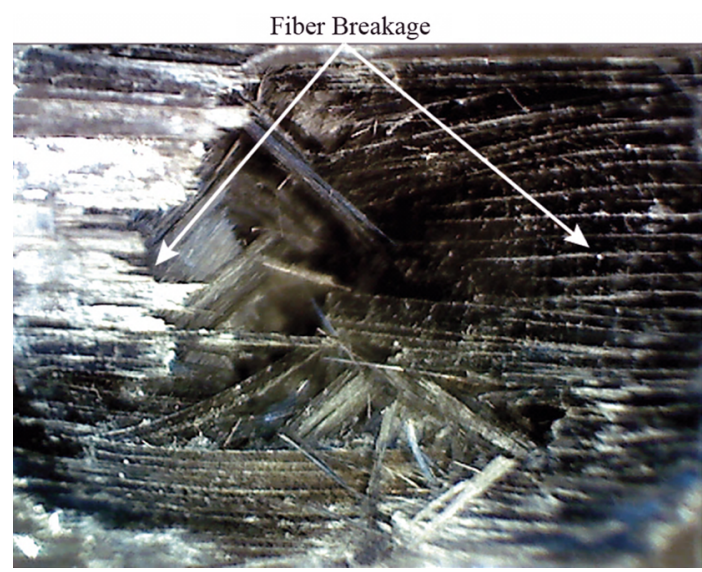

Fig. 3. Fiber breakage in the first two layers of Specimen 1.

and a window-based data acquisition program was developed in LabVIEW 2010 to obtain the impact force and absorbed energy history. The total mass $(\mathrm{m})$, including the impactor, load cell, and add-on weights, was $3.44 \mathrm{~kg}$. The impactor drop height $(h)$ was $0.70 \mathrm{~m}$, and the impact velocity $\left(v_{\mathrm{o}}\right)$ was $3.71 \mathrm{~m} / \mathrm{s}$, which was calculated by using $v_{0}=\sqrt{2 g h}$, where $g$ is the earth's gravity constant. The machine consisted of three main parts: a drop weight tower, a base plate which holds the specimen, and a control unit housing. When the cylindrical impactor with a hemispherical head having a radius of $6.5 \mathrm{~mm}$ struck the center of the specimen, the data were automatically recorded in the computer by the LabVIEW program. Three impact tests were done for each case.

\section{Results and Discussion}

\subsection{Analysis of impact damage}

The impact damage mechanism in a composite laminate is a highly complex process because it is a combination of damage processes, including matrix cracking, surface buckling, delamination, fiber breakage, and fiber splitting. These damage mechanisms usually interact with each other in low-velocity impact

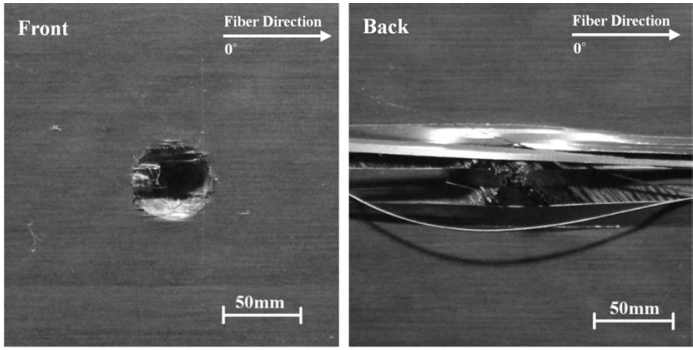

(a) Specimen $1,[0 / 45 /-45 / 90]$,

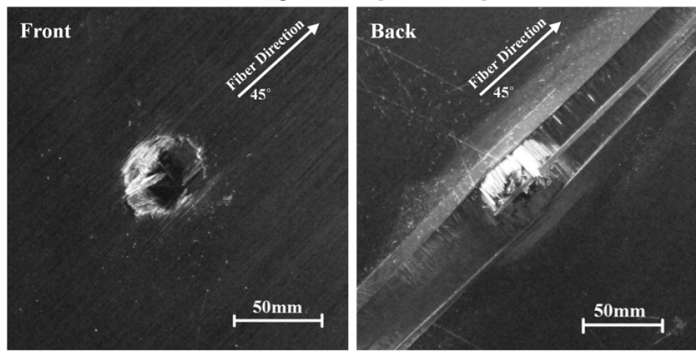

(b) Specimen 2, [45/-45/0/90]

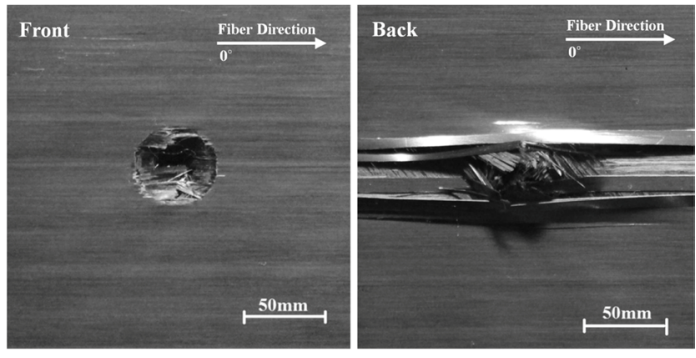

(c) Specimen 3, [0/45/90/-45]
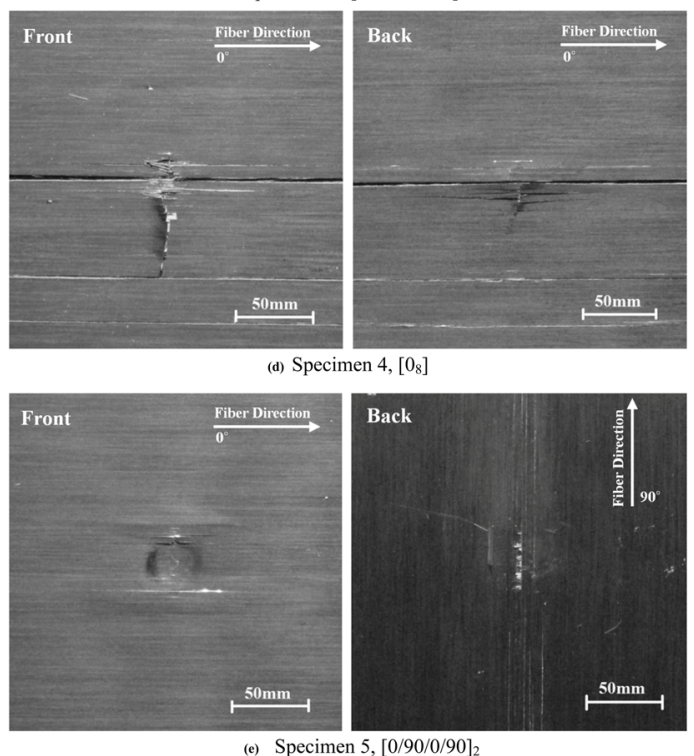

Fig. 4. The front and back surfaces of all the specimens.

tests. A composite plate is made up of several orthotropic layers and each layer tends to deform in a particular way. Transverse normal and shear stresses were applied at the interfaces, and delamination occurred when these inter-laminar stresses became too large under concentrated contact loads. Delamination in a composite laminate is caused by the mismatch between the 


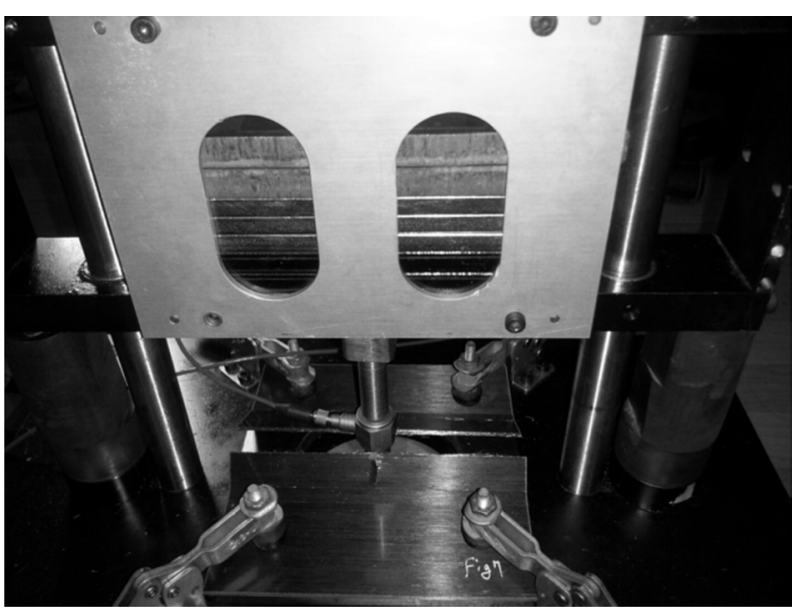

Fig. 5. An image of specimen 4 broken in half after impact.

bending stiffness of the plies with different fiber orientations, and it propagates along the direction of the fibers [17]. The delamination pattern is dependent upon the stacking sequence of the composite plate. A delamination crack preferentially propagates through a matrix rich area, which is relatively less resistant than that of a fiber pathway [18]. Delamination of the plies is the primary damage mode in a low-velocity impact test, and the delamination energy is directly related to the damage size. The largest delamination damage generally occurs at the back face and becomes progressively smaller toward the impact face.

When an impactor was dropped onto Specimen 1, the plate was perforated. Fiber breakage was found at the centrally depressed zone on the impacted face of the plate shown in Fig. 3 , although major damage mechanisms were not present in the quasi-isotropic (Specimen 1) composite laminate. Fiber breakage occurs under the impactor due to locally high stresses and indentation effects.

The front and back sides of each specimen after the impact test are shown in Fig. 4. Fig. 4a shows the damage pattern, shape, and size on the impacted and back faces of Specimen 1. On the front side of the specimen, the damage shape was more or less circular. The back face of the plate showed that delamination occurred between the last two layers of the plate. The impacted and back faces of Specimens 2 and 3 are shown in Fig. $4 \mathrm{~b}$ and c, respectively. Specimens 1-3 are all the quasi-isotropic type and all showed similar damage patterns on the impacted and back faces of the plate. The large mismatch between the bending stiffness in the quasi-isotropic layers caused the large delamination.

In the case of the unidirectional composite plate (Specimen 4), the plate was completely broken into two parts, resulting in no penetration of the impactor shown in Fig. 5. When the impactor hit the front side of the plate, matrix cracking occurred along the fiber direction and through the entire thickness of the plate. Compared to the quasi-isotropic plates, delamination between the last two layers and in the middle of the specimen depth was also observed shown in Fig. 6. Some matrix cracking was also observed along the fiber and transverse directions on the front and back sides of the plate shown in Fig. 4d. Because there was no bending stiffness mismatch in the unidirectional layers, only

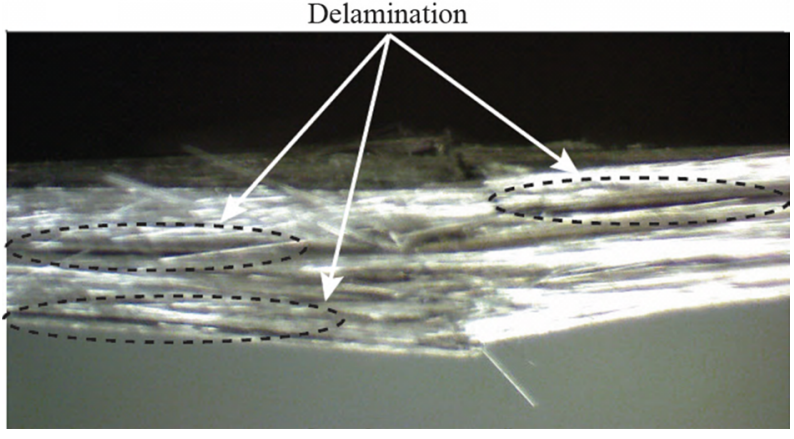

Fig. 6. A cross-sectional view of specimen 4 after impact.

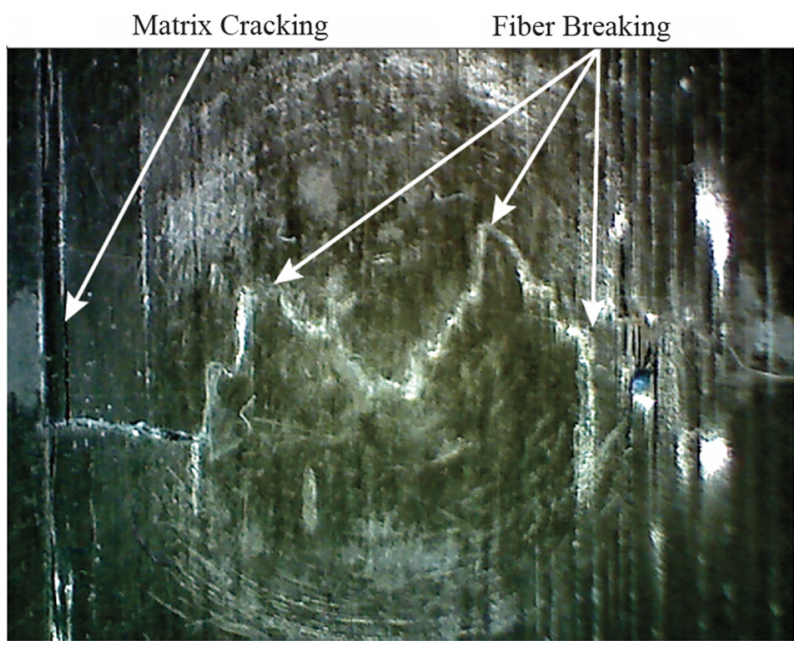

Fig. 7. The damage to the front surfaces of the cross-ply specimen.

a small delamination took place between the layers. In the case of cross-ply Specimen 5, the impactor did not penetrate through the plate, but a small dent on the impacted side was observed. On the impacted side, different damage mechanisms like matrix cracking, crushing, and fibers breakage were observed shown in Fig. 7. On the back side, a small delamination between the last two layers took place due to stiffness mismatch shown in Fig. 4e.

\subsection{Force-time data}

The impact force versus time curves provide a comprehensive depiction of the damage initiation and growth, as well as the changes in the specimen stiffness [19]. During the impact loading stage of the perforated plate case (Specimen 3), shown as point $S_{0}$ to $S_{1}$ in Fig. 8, the hemi-spherical head of the impactor started to contact the normal surface of the specimen, and as a result, it showed regular undulations, and then, a sudden load drop occurred at the beginning of the strike for all the specimens due to the local initiation of contact damages. Up to point $S_{1}$, the sudden decrease is referred to as a Hertzian failure, which indicates that the incipient damage is mainly in the form of micro-matrix cracking and small inter-laminar delamination in the plate. This also indicates the specimen's abrupt transition from an intact state to a damaged state. Therefore, this stage can be re- 


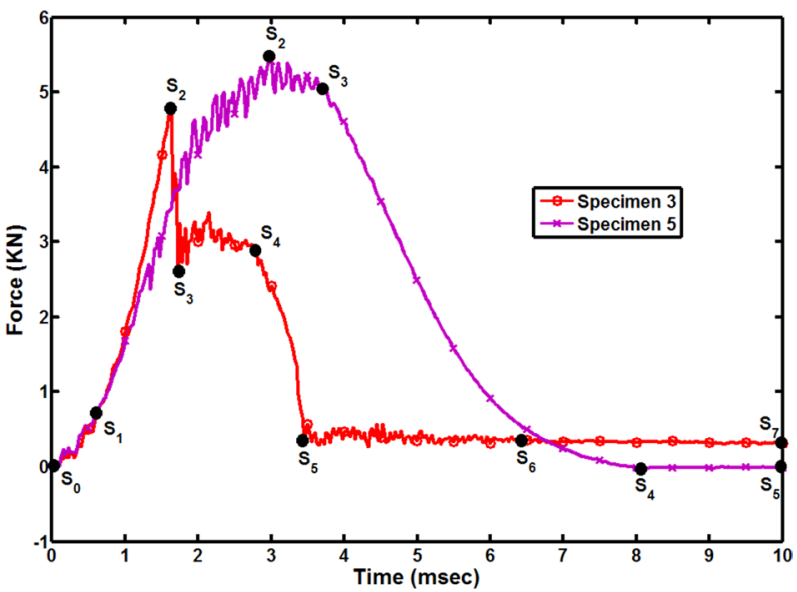

Fig. 8. The impact force history diagram for Specimens 3 and 5.

garded as the initiation of the impact damage. From points $S_{1}$ to $\mathrm{S}_{2}$, the impact force reached its peak value with no undulations, in the short time of approximately $1.5 \mathrm{~ms}$. The impact damage developed quickly in this stage shown in Fig. 8. The peak load at point $S_{2}$ rapidly dropped down to point $S_{3}$, with undulations that were due to the rapid extension of delamination through the thickest direction of the specimen. After the rapid extension of the matrix dominant delamination up to point $\mathrm{S}_{3}$, some local breakages of fiber dominant layers started to increase the decaying force undulations until point $\mathrm{S}_{4}$. At point $\mathrm{S}_{4}$, the force suddenly decreased down to point $\mathrm{S}_{5}$, at which almost all of the remaining fiber dominant layers were broken and a sharp fall in the force curve occurred, due to the loose contact between the specimen and the impactor. Minor fluctuations of the force happened between $\mathrm{S}_{5}$ to $\mathrm{S}_{6}$, due to additional minor matrix cracking and the failure of the remaining local fibers. The last stage of the impact process is from point $S_{6}$ to $S_{7}$, and there was no further damage development in this stage.

For the rebounding case (Specimen 5) in Fig. 8, the small undulations from points $\mathrm{S}_{0}$ to $\mathrm{S}_{1}$ might be due to the initial contact between the hemi-spherical head of the impactor with the specimen surface, and this initiates the formation of small matrix cracking and delamination in the plate. The impact force reached its peak level with the undulations, and maximum matrix cracking, fiber breakage and delamination occurred between points $S_{1}$ and $S_{2}$. After reaching the peak load at point $S_{2}$, local breakages of the fiber dominant layers started to produce force undulations until point $S_{3}$. At point $S_{3}$, the force started to drop down to point $\mathrm{S}_{4}$ when the impactor was also bouncing back, and there was no further damage development in this stage. The last stage is from point $S_{4}$ to $S_{5}$, when the impactor stopped after bouncing back.

The impact forces versus time histories for all of the specimens are shown in Fig. 9. By comparing the impact force histories, it was noted that the unidirectional composite plate had the lowest impact peak force. The cross-ply composite plate had the highest impact peak force as well as the largest impulse area, among the force and time history curves of all the specimens. This means that the impactor and plate had a long contact time, and a high impact load was applied to Specimen 5. The unidirectional composite plate had the shortest contact time because the

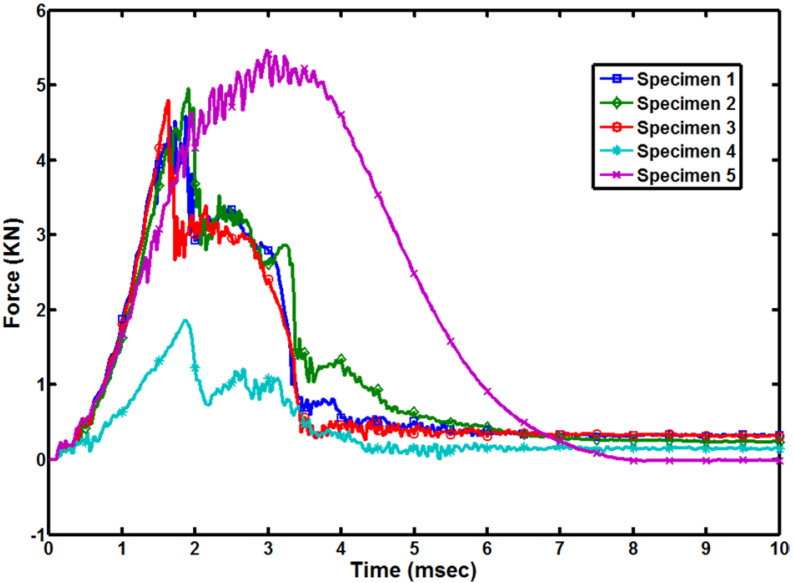

Fig. 9. The impact force versus time diagram.

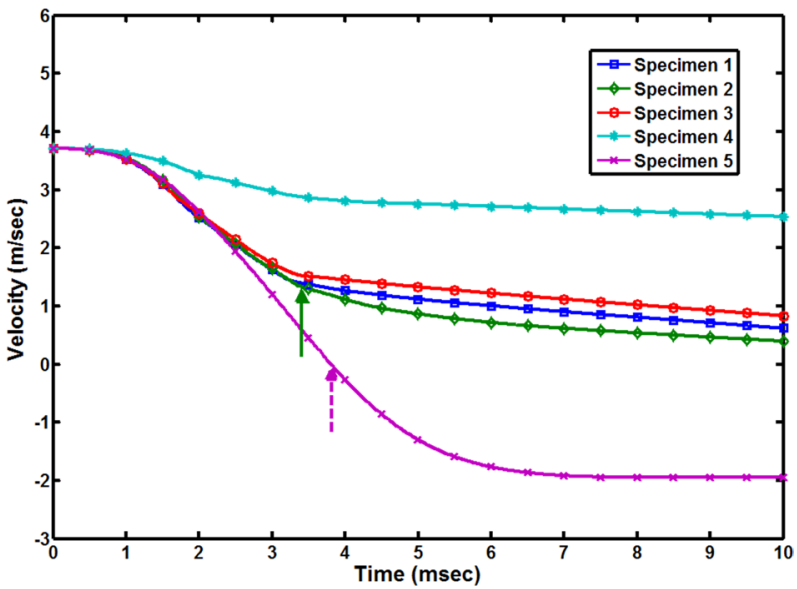

Fig. 10. The impactor velocity versus time diagram.

panel broke into two parts along the fiber direction immediately after the impact, ending up with no penetration of the impactor into the plate. This time was followed by the quasi-isotropic composite plates, and the cross-ply composite plate had the longest contact time. All of the quasi-isotropic composites showed similar levels of impact peak force, which was much higher than that for the unidirectional, but lower than that of the cross-ply composite.

The curves of the impactor velocities versus time for all of the specimen types are shown in Fig. 10. After the transition time at approximately $3.4 \mathrm{~ms}$ for the quasi-isotropic specimens, the velocity of the impactor head decreased almost linearly and reached zero when the impactor stopped. For unidirectional Specimen 4, it was observed that a small reduction in the impactor velocity, corresponding to a small deceleration, occurred after the impactor struck Specimen 4, and the impactor continued further with a slightly decreased velocity even after breaking the plate into two parts. For cross-ply Specimen 5, the impactor velocity became zero, and the impactor began to rebound upward immediately after a transition time of approximately 3.8 ms, which is marked by a dashed arrow.

The impactor displacements versus time curves for all the 


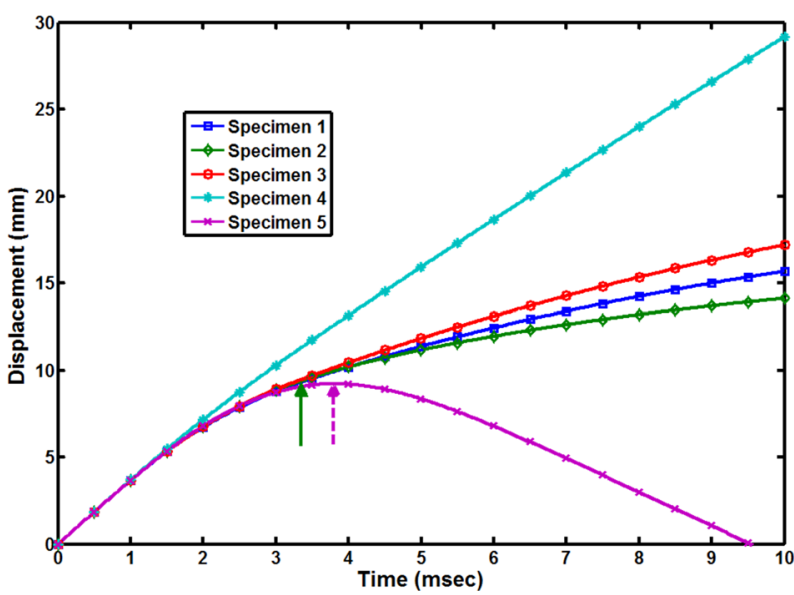

Fig. 11. The impactor displacement versus time diagram.

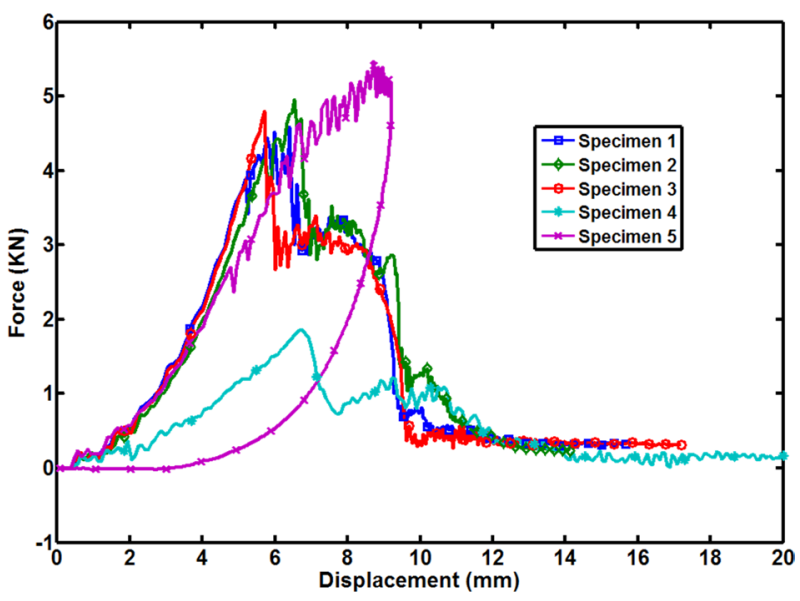

Fig. 12. The impact force versus displacement diagram.

specimens are shown in Fig. 11. In the case of plate perforation, the impactor penetrates further through the thickness of Specimen 3 compared to the other two quasi-isotropic composite plates, Specimens 1 and 2. For the quasi-isotropic specimens, the transition time (marked by a solid arrow in Fig. 11) was observed at approximately $3.4 \mathrm{~ms}$, after which the displacements of the impactor for Specimens 1-3 began to increase in an almost a linear manner until the impactor finally stopped due to the friction between the penetrated circular edge of the plate and the impactor. When unidirectional Specimen 4 clearly broke into two parts, as shown in Fig. 5, it was observed that the impactor kept moving down, which further increased its displacement with no barrier shown in Fig. 11. For Specimen 5, the impactor started to bounce back after reaching its maximum displacement (or the maximum deflection of the plate at the impact point) without penetration at approximately $3.8 \mathrm{~ms}$ (marked by a dashed arrow) and returned to its original position at zero displacement when it was completely detached from the surface of the plate.

The impact force versus displacement curves for the five specimens with different stacking sequences are shown in Fig. 12. The areas of these curves represent the kinetic energies which were transferred to the composite plates during the impact. In this figure, the rebound and/or penetration characteristics of

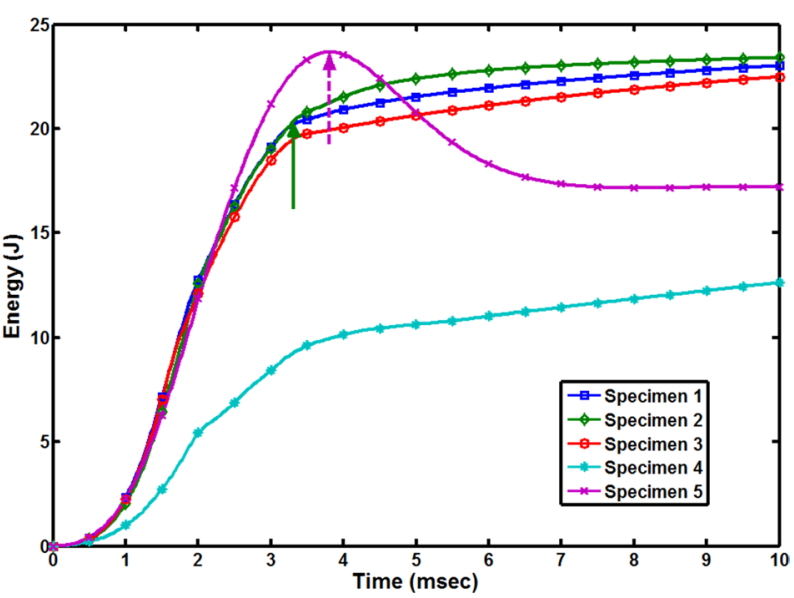

Fig. 13. The absorbed energy versus time diagram.

the impactor are clearly observed. For the cross-ply composite plate, the impactor rebounded, and the force-displacement curve folded into itself toward the decreasing displacement, while for the unidirectional and quasi-isotropic composite plates, the impactor penetrated through the plates, and the displacement increased monotonically but with decreasing force.

\subsection{Absorbed energy}

Under the same level of impact energy, the energy absorbed by the composite plates versus the time histories is shown in Fig. 13. The total energy $(E)$ absorbed by the specimens was calculated with Eq. (1) as:

$$
\begin{aligned}
& E=E_{a}\left(1-\frac{E_{a}}{4 E_{o}}\right) \\
& E_{a}=v_{o} \int F d t \\
& E_{o}=\frac{1}{2} m v_{o}^{2}
\end{aligned}
$$

, where $v_{\mathrm{o}}$ is the velocity at impact; $F$ is the force exerted by the impactor on the specimen, and $m$ is the mass of impactor. Lowvelocity impact tests were performed on five different stacking sequences of the CFRP composite plates that can be categorized into three cases: plate perforated, broke into two parts, and no perforation or penetration. In the initial stages, the absorbed energy values for all five specimens were low, which can be attributed to the small dent in the plates and the deformation along the thickness direction at the point of contact between the impactor and the plates under the low-velocity impact loading shown in Fig. 13. After that, the absorbed energy curve for the cross-ply specimen increased progressively until the maximum displacement (marked by a dashed arrow) of the impactor was reached, while the curves for the quasi-isotropic and unidirectional specimens approached their maximum values. The slope of all of the energy curves increased quickly between the time periods of 1 to $2 \mathrm{~ms}$. This increase in the slope of the energy curves represents the maximum deflection of the plates and the start of internal damage in the plates. Thus, in this stage, the absorbed energy 


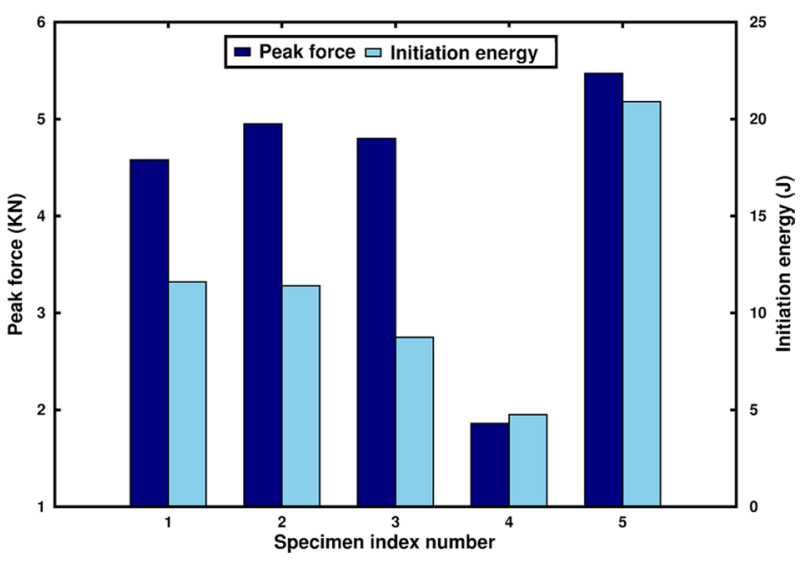

Fig. 14. The impact force and initiation energy of all specimens.

is mainly due to the maximal contact between the impactor and plates. All of the quasi-isotropic composite plates absorbed approximately the same level of impact energy over the transition time, but after that, the energy curves appeared to further increase because of the friction between the lateral surface of the impactor and the penetrated circular edge of each specimen. After approximately $3.4 \mathrm{~ms}$, in the force versus time diagrams, both the force value and the area under the curve for Specimen 2 were higher than those for Specimens 1 and 3. These reasons explain why the absorbed energy value for Specimen 2 was greater than that of the other two quasi-isotropic composite plates. As the unidirectional plate was broken into two parts, the friction between the plate and the impactor was sufficiently small that it absorbed less energy compared to the other composite plates. For the rebound case, the curve progressively decreased as the impactor started to rebound until the impactor completely detached from the plate and stopped. It is reasonable to suppose that the specimen did not absorb any further energy after this point.

The load-time history can be divided into two distinct regions: the region of fracture initiation and the region of fracture propagation. The initiation energy $\left(E_{\mathrm{i}}\right)$ required for a fracture eruption in a plate can be defined as the energy absorbed by a plate up to the peak load in the force-time diagram (Fig. 9). Because the impactor penetrated through the quasi-isotropic specimens, the unidirectional specimen was broken into two parts, and the impactor rebounded after hitting the cross-ply specimen, it is reasonable to compare the initiation energy values for all of the specimens to investigate the penetration-resistant behavior of composite plates shown in Fig. 14. The cross-ply specimen absorbed the highest initiation energy of all the specimens, and the initiation energy absorbed by the unidirectional specimen was the lowest.

The peak load and initiation energy values for the quasi-isotropic specimens were approximately the same. To determine how much energy was absorbed by the specimen from the applied energy, the absorbed energy ratio, the percentage $R(\%)$, is introduced in Eq. (4).

$R(\%)=\frac{\text { Initiation Energy }\left(E_{i}\right)}{\text { Applied Energy }\left(E_{o}\right)} \times 100$

The energy ratio, the value of the initiation energy of a com-
Table 3. Parametric comparisons of the experimental results

\begin{tabular}{cccccc}
$\begin{array}{c}\text { Index } \\
\text { No. }\end{array}$ & $\begin{array}{c}\text { Peak } \\
\text { rorce } \\
(\mathrm{KN})\end{array}$ & $\begin{array}{c}\text { Initiation } \\
\text { energy } \\
(\mathrm{J})\end{array}$ & $\mathrm{R}(\%)$ & $\begin{array}{c}\text { Energy } \\
\text { ratio }\end{array}$ & $\begin{array}{c}\text { Residual } \\
\text { energy } \\
(\mathrm{J})\end{array}$ \\
\hline 1 & 4.58 & 11.6 & 49.1 & 0.55 & 11.27 \\
2 & 4.95 & 11.4 & 48.1 & 0.54 & 11.84 \\
3 & 4.80 & 8.74 & 37.0 & 0.42 & 13.62 \\
4 & 1.86 & 4.75 & 20.1 & 0.23 & 7.84 \\
5 & 5.47 & 20.9 & 88.6 & 1.00 & 2.57 \\
\hline
\end{tabular}

posite plate normalized with respect to that of the cross-ply composite plate, was defined by Eq. (5) for the purpose of comparing the different composite laminates. These $R(\%)$ and energy ratios $(E R)$ for each composite plate are listed in Table 3.

$$
\text { Energy Ratio }=\frac{\text { Initiation Energy by Specimen }}{\text { Initiation Energy by Crossply }}
$$

Another finding from the low-velocity impact data was the further increase in the absorbed energy after the peak force or initiation energy had been reached (i.e., after $E_{\mathrm{i}}$ ). It is reasonable to assume that all damages have been produced when the energy curve reached a maximum absorbed energy $\left(E_{\max }\right)$ point, which corresponds to the penetration of the impactor or the maximum deflection value of the composite plate. The energy absorbed by the composite plate between the initiation energy point $\left(E_{\mathrm{j}}\right)$ and the maximum energy point $\left(E_{\max }\right)$ is used in the extension of the delamination or damage process and referred to as the residual energy $\left(E_{\mathrm{r}}\right)$, defined by Eq. (6). The residual energies for the five composite plates for dry conditions are listed in Table 3. Specimen 3 absorbed the maximum energy from the extensive damage process, and the minimum was absorbed by the crossply (Specimen 5).

$$
E_{r}=E_{\text {max }}-E_{i}
$$

In classical lamination plate theory [20], the strain energy $(U)$ stored in a laminated composite plate that is subjected to a quasistatic normal load on the plate surface, in which the dynamic kinetic energy terms are not considered can be expressed by Eq. (6).

$$
U=\frac{1}{2} \iint_{0}^{L_{x} L_{y}}\left\{\begin{array}{l}
\varepsilon^{o} \\
k
\end{array}\right\}^{T}\left[\begin{array}{ll}
A & B \\
B & D
\end{array}\right]\left\{\begin{array}{l}
\varepsilon^{o} \\
k
\end{array}\right\} d x d y
$$

, where $A, B$, and $D$ are the extensional, coupling, and bending stiffness matrixes, respectively. $\varepsilon^{\mathrm{o}}\left(=\left\{\varepsilon_{\mathrm{x}}^{\mathrm{o}} \varepsilon_{\mathrm{y}}^{\mathrm{o}} \gamma_{\mathrm{xy}}^{\mathrm{o}}\right\}^{T}\right)$ and $\kappa\left(=\left\{\kappa_{\mathrm{x}}\right.\right.$ $\left.\kappa_{\mathrm{y}} \kappa_{\mathrm{xy}}\right\}^{T}$ ) are the mid-plane strain and curvature column matrices, respectively. The superscript ' $T$ ' indicates the transpose of a matrix. $L_{\mathrm{x}}$ and $L_{\mathrm{y}}$ are the $\mathrm{x}$ - and y-directional lengths of the plate. It should be noted that for the quasi-isotropic composite plates with balanced and symmetric layup, $A_{\text {is }}=0(i=x, y)$ and $B=0$, while for the cross-ply composite plate with an anti-symmetric layup, $B \neq 0$. For a simply supported plate with a symmetric layup that is subjected to out-of-plane loads, only the strains in 
the mid-plane become zero $\left(\varepsilon^{\circ}=0\right)$, and the strain energy in Eq. (7) is simplified as Eq. (8).

$$
\begin{aligned}
U & =\frac{1}{2} \iint_{00}^{L_{x} L_{y}} k^{T} D k d x d y \\
& =\frac{1}{2} \iint_{00}^{L_{x} L_{y}}\left[D_{x x} k_{x}{ }^{2}+D_{y y} k_{x y}{ }^{2}+D_{s s}\left(2 k_{x y}\right)^{2}\right. \\
& \left.+2\left(D_{x y} k_{x} k_{y}+2 D_{x s} k_{x} k_{x y}+2 D_{y s} k_{y} k_{x y}\right)\right] d x d y \\
D & =\left[\begin{array}{lll}
D_{\mathrm{xx}} & D_{\mathrm{xy}} & D_{\mathrm{xs}} \\
D_{\mathrm{xy}} & D_{\mathrm{yy}} & D_{\mathrm{ys}} \\
D_{\mathrm{xs}} & D_{\mathrm{ys}} & D_{\mathrm{ss}}
\end{array}\right]
\end{aligned}
$$

If only the contribution of the bending stiffness matrix in the strain energy is considered and any types of dynamic effects on the stored strain energy are disregarded, and then, the strain energy stored in the laminated composite plate with no warpage, i.e., $k_{\mathrm{xy}}=0$, becomes partially proportional to the value of $D_{\mathrm{xx}} k_{\mathrm{x}}^{2}+D_{\mathrm{yy}} k_{\mathrm{y}}^{2}+2 D_{\mathrm{xy}} k_{\mathrm{x}} k_{\mathrm{y}}$ which is related to the bending stiffness components, $D_{\mathrm{xx}}, D_{\mathrm{yy}}$, and $D_{\mathrm{xy}}$ that relate the applied moments to the deformed curvatures. If it is assumed that the curvatures $\kappa_{\mathrm{x}}$ and $\kappa_{\mathrm{y}}$ are the same for the square plates $\left(L_{\mathrm{x}}=L_{\mathrm{y}}\right)$, and that $\kappa_{\mathrm{xy}}$ is zero for the deformed shape of a composite plate during the impact event, then the strain energy is thought to be partially proportional to $D^{*}=D_{\mathrm{xx}}+D_{\mathrm{yy}}+2 D_{\mathrm{xy}}$ for a given plate curvature $\kappa_{\mathrm{x}} . D^{*}$ is considered only for the parametric study on the impact resistant behavior of the composite plate with the assumption of the same $\kappa_{\mathrm{x}}\left(=\kappa_{\mathrm{y}}\right)$ for all of the composite plates. Interestingly, $D^{*}$ for each composite plate had approximately the same value of $43.90 \mathrm{~N}-\mathrm{m}$. This shows that the differences in the impact resistant behavior between the quasi-isotropic symmetric composite plates $\left(B_{\mathrm{ij}}=0, i, j=x, y, s\right)$ and the cross-ply composite plate $\left(B_{\mathrm{ij}}\right.$ $=0$ except $B_{\mathrm{xx}}=-B_{\mathrm{yy}}=-9.5 \mathrm{GPa} \cdot \mathrm{mm}^{2}$ ) are primarily due to the differences in the $B$ matrix and the different curvatures of those two types of composite plates rather than the contribution of the $D^{*}$ approach.

\section{Conclusions}

This study presented an experimental investigation on the impact response of CFRP composite plates made by different stack-up configurations although the geometry, boundary condition, and material are identical. The following conclusive remarks are drawn from this study. From the force and energy histories, it was observed that the stacking sequence has a major effect on the impact parameters under low-velocity impact events. The unidirectional composite plate had the worst impact resistance followed by three different quasi-isotropic plates, while the cross-ply plate sustained the largest impact force and absorbed the largest energy; therefore, it is reasonable to conclude that this specific stacking sequence is preferable compared with the other composite plates. Under the same level of impact energy, the impactor penetrated through the quasi-isotropic composite plates, and a unidirectional plate was broken into two parts, while the impactor rebounded in the case of the cross-ply composite plate. The three different quasi-isotropic composite plates had similar damage patterns and impact behaviors. The $D^{*}$ value for all of the composite plates was the same; therefore, under the same level of impact energy, the cross-ply composite plate exhibited the maximum resistance to impact compared to the other composite plates because of a non-zero coupling matrix $(B \neq 0)$.

\section{References}

[1] Foster GC. Tensile and flexure strength of unidirectional fiberreinforced composites: direct numerical simulations and analytic models [MS Thesis], Virginia Polytechnic Institute and State University, Blacksburg, VA (1998).

[2] Mangalgiri PD. Composite materials for aerospace applications. Bull Mater Sci, 22, 657 (1999). http://dx.doi.org/10.1007/ BF02749982.

[3] Li CF, Hu N, Yin YJ, Sekine H, Fukunaga H. Low-velocity impactinduced damage of continuous fiber-reinforced composite laminates. Part I. An FEM numerical model. Composites A, 33, 1055 (2002). http://dx.doi.org/10.1016/S1359-835X(02)00081-7.

[4] Li CF, Hu N, Cheng JG, Fukunaga H, Sekine H. Low-velocity impact-induced damage of continuous fiber-reinforced composite laminates. Part II. Verification and numerical investigation. Composites A, 33, 1063 (2002). http://dx.doi.org/10.1016/S1359835X(02)00078-7.

[5] Sekine H, Hu N, Fukunaga H, Natsume T. Low-velocity impact response of composite laminates with a delamination. Mech Compos Mater Struct, 5, 257 (1998). http://dx.doi. org/10.1080/10759419808945901.

[6] Sun CT. An analytical method for evaluation of impact damage energy of laminated composites. Am Soc Test Mater STP, 617, 427 (1977).

[7] Aslan Z, Karakuzu R, Okutan B. The response of laminated composite plates under low-velocity impact loading. Compos Struct, 59, 119 (2003). http://dx.doi.org/10.1016/S0263-8223(02)00185$\mathrm{X}$

[8] Naik NK, Chandra Sekher Y, Meduri S. Damage in woven-fabric composites subjected to low-velocity impact. Compos Sci Technol, 60, 731 (2000). http://dx.doi.org/10.1016/S0266-3538(99)001839.

[9] Siow YP, Shim VPW. An experimental study of low velocity impact damage in woven fiber composites. Compos Mater, 32, 1178 (1998). http://dx.doi.org/10.1177/002199839803201203.

[10] Yang SH, Sun CT. Indentation law for composite laminates. Am Soc Test Mater STP, 787, 425 (1981

[11] Choi IH, Lim CH. Low-velocity impact analysis of composite laminates using linearized contact law. Compos Struct, 66, 125 (2004). http://dx.doi.org/10.1016/j.compstruct.2004.04.030.

[12] Sun CT, Chattopadhyay S. Dynamic response of anisotropic laminated plates under initial stress to impact of a mass. J Appl Mech, 42, 693 (1975). http://dx.doi.org/10.1115/1.3423664.

[13] Dobyns AL. Analysis of simply supported orthotropic plates subject to static and dynamic loads. AIAA J, 19, 642 (1981). http:// dx.doi.org/10.2514/3.50984.

[14] Ramkumar RL, Chen PC. Low-velocity impact response of laminated plates. AIAA J, 21, 1448 (1983). http://dx.doi org/10.2514/3.8266.

[15] Whitney JM, Pagano NJ. Shear deformation in heterogeneous 
anisotropic plates. J Appl Mech, 37, 1031 (1970). http://dx.doi. org/10.1115/1.3408654.

[16] Ganapathy S, Rao KP. Interlaminar stress in laminated composite plates, cylindrical/spherical shell panels damaged by low-velocity impact. Compos Struct, 38, 157 (1997). http://dx.doi.org/10.1016/ S0263-8223(97)00052-4.

[17] Liu D. Impact-induced delamination: a view of bending stiffness mismatching. J Compos Mater, 22, 674 (1988). http://dx.doi. org/10.1177/002199838802200706.
[18] Azouaoui K, Azari Z, Pluvinage G. Evaluation of impact damage in glass/epoxy composite laminate. Int J Fatigue, 32, 443 (2010). http://dx.doi.org/10.1016/j.ijfatigue.2009.09.005.

[19] Schoeppner GA, Abrate S. Delamination threshold loads for low velocity impact on composite laminates. Composite A, 31, 903 (2000). http://dx.doi.org/10.1016/S1359-835X(00)00061-0.

[20] Kollár LP, Springer GS. Mechanics of Composite Structures, Cambridge University Press, New York, NY (2003). 